\title{
DECLARATION OF HELSINKI
}

\section{Recommendations Guiding Doctors in Clinical Research}

\section{Introduction}

It is the mission of the doctor to safeguard the health of the people. His knowledge and conscience are dedicated to the fulfillment of this mission.

The Declaration of Geneva of The World Medical Association binds the doctor with the words: "The health of my patient will be my first consideration" and the International Code of Medical Ethics which declares that "Any act or advice which could weaken physical or mental resistance of a human being may be used only in his interest."

Because it is essential that the results of laboratory experiments be applied to human beings to further scientific knowledge and to help suffering humanity, The World Medical Association has prepared the following recommendations as a guide to each doctor in clinical research. It must be stressed that the standards as drafted are only a guide to physicians all over the world. Doctors are not relieved from criminal, civil and ethical responsibilities under the laws of their own countries.

In the field of clinical research a fundamental distinction must be recognized between clinical research in which the aim is essentially therapeutic for a patient, and the clinical research, the essential object of which is purely scientific and without therapeutic value to the person subjected to the research.

\section{Basic principles}

1. Clinical research must conform to the moral and scientific principles that justify medical research and should be based on laboratory and animal experiments or other scientifically established facts.

2. Clinical research should be conducted only by scientifically qualified persons and under the supervision of a qualified medical man.

3. Clinical research cannot legitimately be carried out unless the importance of the objective is in proportion to the inherent risk to the subject.

4. Every clinical research project should be preceded by careful assessment of inherent risks in comparison to forseeable benefits to the subject or to others.

5. Special caution should be exercised by the doctor in performing clinical research in which the personality of the subject is liable to be altered by drugs or experimental procedure.

\section{Clinical research combined with professional care}

1. In the treatment of the sick person, the doctor must be free to use a new therapeutic measure, if in his judgment it offers hope of saving life, reestablishing health, or alleviating suffering.

If at all possible, consistent with patient psychology, the doctor should obtain the patient's freely given consent after the patient has been given a full explanation. In case of legal incapacity, consent should also be procured from the legal guardian; in case of physical incapacity the permission of the legal guardian replaces that of the patient.

2. The doctor can combine clinical research with professional care, the objective being the acquisition of new medical knowledge, only to the extent that clinical research is justified by its therapeutic value for the patient.

\section{Non-therapeutic clinical research}

1. In the purely scientific application of clinical research carried out on a human being, it is the duty of the doctor to remain the protector of the life and health of that person on whom clinical research is being carried out.

2. The nature, the purpose and the risk of clinical research must be explained to the subject by the doctor.

3a. Clinical research on a human being cannot be undertaken without his free consent after he has been informed; if he is legally incompetent, the consent of the legal guardian should be procured.

$3 \mathrm{~b}$. The subject of clinical research should be in such a mental, physical and legal state as to be able to exercise fully his power of choice.

3c. Consent should, as a rule, be obtained in writing. However, the responsibility for clinical research always remains with the research worker; it never falls on the subject even after consent is obtained.

4a. The investigator must respect the right of each individual to safeguard his personal integrity, especially if the subject is in a dependent relationship to the investigator.

4b. At any time during the course of clinical research the subject or his guardian should be free to withdraw permission for research to be continued.

The investigator or the investigating team should discontinue the research if in his or their judgment, it may, if continued, be harmful to the individual. 